\title{
Ependymal cells surface of human third brain ventricle by scanning electron microscopy
}

\author{
Lorencova $\mathrm{M}^{1}$, Mitro $\mathrm{A}^{1}$, Jurikova $\mathrm{M}^{1}$, Galfiova $\mathrm{P}^{1}$, Mikusova $\mathrm{R}^{1}$, Krivosikova $\mathrm{L}^{2}$, Janegova $\mathrm{A}^{2}$, \\ Palkovic $\mathrm{M}^{2}$, Polak $\mathrm{S}^{1}$
}

Institute of Histology and Embryology, Faculty of Medicine, Comenius University, Bratislava, Slovakia. paulina.galfiova@fmed.uniba.sk

\begin{abstract}
OBJECTIVES: The ependymal lining of the human brain ventricular system displays distinct structural differences and functional heterogeneity among individual ependymal cells (ECs). To date, multi-ciliated ECs (E1 cells), bi-ciliated ECs (E2 cells), uni-ciliated ECs (E3 cells), ECs without cilia, and ECs with cytoplasmic protrusions have been described in human brain ventricles.

METHOD: Using scanning electron microscopy (SEM), we evaluated ependymal samples from 6 defined regions of the third ventricle from 9 human brains. These regions were strictly defined according to the periventricular structures they neighbour with.

RESULTS: We observed different structures on the apical surface of the ECs. Various ECs differed from each other by the presence of microvilli, secretory bodies, and a variable number of cilia, which led us to divide the ECs into several exactly specified types according to their apical morphology.

CONCLUSION: We found all types of ECs in every examined region with a predominance of particular types of apical surface of ECs in the individual areas (Tab. 4, Fig. 7, Ref. 22). Text in PDF www.elis.sk. KEY WORDS: human central nervous system, third brain ventricle, ependymal areas, surface of ependymal cells.
\end{abstract}

\section{Introduction}

Ependymal cells (ECs) form the lining of the walls of the brain ventricles. They are special glial cells of the central nervous system. In humans as well as animals, ECs originate from the subpopulation of radial glial cells and differentiate at the exact time of development (1-4).

In general, mature ECs display a squamous, cuboidal, or columnar shape, a regular round slightly hyperchromatic nucleus (granular chromatin), and an inconspicuous nucleolus. They exhibit morphological and functional polarity. The apical portion of cells' cytoplasm lodges numerous mitochondria. On the apical surface of ECs many microvilli, cytoplasmic protrusions, and clusters of motile cilia are present in most of the cells. The ECs are in direct contact with the environments of different physical properties. The apical side of ECs is in contact with the cerebrospinal fluid (CSF) while the basal portion borders various structures

${ }^{1}$ Institute of Histology and Embryology, Faculty of Medicine, Comenius University, Bratislava, Slovakia, and 'Institute of Pathology, Faculty of Medicine, Comenius University, Bratislava, Slovakia

Address for correspondence: P. Galfiova, MD, PhD, Institute of Histology and Embryology, Faculty of Medicine, Comenius University in Bratislava, Sasinkova 4, SK-811 08 Bratislava, Slovakia.

Phone: +421290119665

Acknowledgment: This study was supported by KEGA Grant No. 074UK4/2019. of the underlying nerve tissue (neurons, nerve fibres, glial cells, blood vessels, and others) (5-8).

When considering the apical surface of ECs, three types of cells were classified in the brain ventricles of human and in mice $(9,10)$. The most common type are multi-ciliated ECs (E1) with numerous motile cilia exhibiting a typical $9+2$ microtubule structure. Bi-ciliated ECs (E2) with one or two motile cilia also exhibit the $9+2$ microtubule structure, but they differ from E1 cells by the presence of specific basal bodies. These basal bodies exhibit raceme-like appendages and cytoskeletal filaments from their sidewall. Uni-ciliated ECs (E3) represent the third type of ECs. They contain one primary non-motile cilia with a $9+0$ arrangement of microtubules and a centriole which is orthogonally positioned to the basal body. A different distribution of ECs was detected in the third ventricle of mice and humans. While the mouse's ventral part of the third ventricle is covered exclusively with E2 and E3 cells and the dorsal part is covered with E1 cells and the border between them is sharp, human ependymal cells do not occupy such definite locations $(9,10)$.

Studies in rats using SEM revealed the presence of cilia, microvilli, cytoplasmic protrusions, supraependymal nerve fibres, and supraependymal cells of various shapes on the apical surface of ECs of the third ventricle $(11,12)$. The ciliary arrangement with 20-30 cilia per EC in the dorsal two thirds of the third ventricle was described as continuous or in tufts. In the ventral third of the third ventricle, ECs mainly possessed microvilli and were mostly devoid of cilia or they displayed scattered solitary cilia. At the 
Tab. 1. Characteristics of the individuals whose third brain ventricles were analysed.

\begin{tabular}{|c|c|c|c|}
\hline $\begin{array}{l}\text { Patient's } \\
\text { number }\end{array}$ & $\begin{array}{c}\text { Age } \\
\text { (years) }\end{array}$ & Sex & Cause of death \\
\hline 1 & 51 & male & generalised kidney tumour \\
\hline 2 & 64 & female & perforated duodenal ulcer \\
\hline 3 & 80 & male & multiple organ failure \\
\hline 4 & 78 & female & myocardial infarction \\
\hline 5 & 61 & male & oesophageal tumour \\
\hline 6 & 72 & female & hepatic failure \\
\hline 7 & 73 & female & cardiac failure \\
\hline 8 & 70 & male & cardiorespiratory failure \\
\hline 9 & 69 & male & cardiorespiratory failure \\
\hline
\end{tabular}
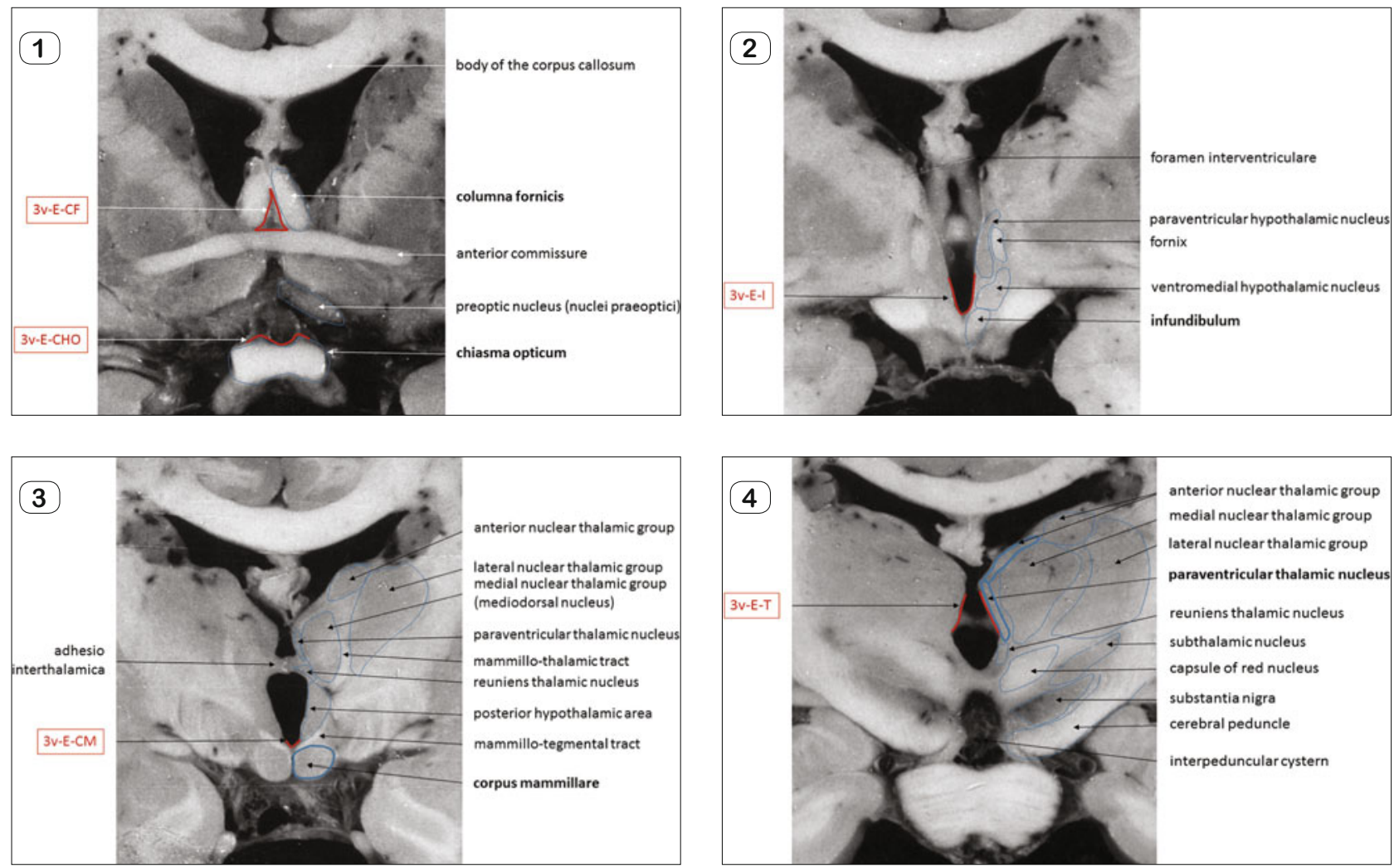

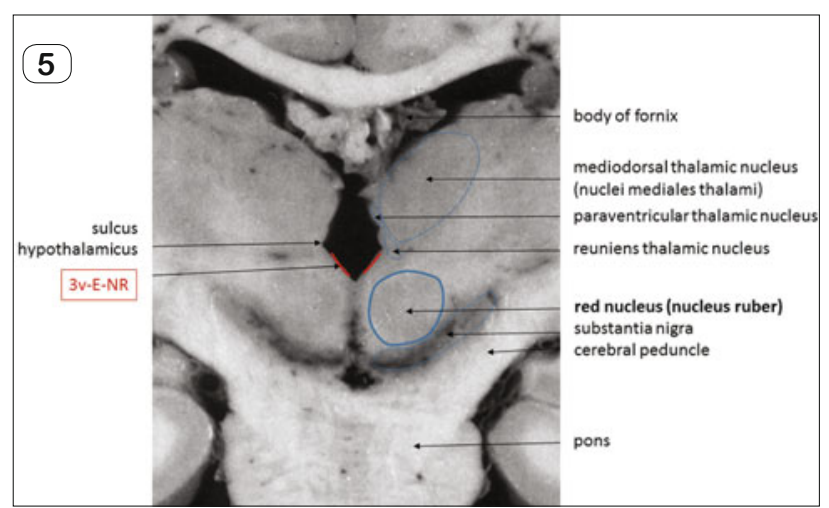

Fig. 1. Frontal sections ( $1-5$ ) of human third ventricle with designated regions (see red rectangles) of examined ependymal lining (see Table 2 ). 
sition between an area with high ciliary density and a non-ciliated ependyma may progress as a gradual change $(15,16)$ and is often designated as a transitional zone with a decreased number of cilia and an abundance of microvilli and miniblebs (17).

Since the ependyma displays many structural variations within the ventricular system $(11,17)$, it is extremely important to determine the exact location of ependyma for tissue sampling so that the samples from different brains can be compared in a relevant way. Because the labelling of individual ependymal areas is not uniform, rather than designating the ependymal areas according to the morphology of cells, we prefer to do so according to the periventricular structures they border (18). Human brain atlases describe 30-35 periventricular structures bordering the third ventricle $(19,20)$. In our previous study, we used 15 periventricular structures to designate individual ependymal areas of the third ventricle (21). With the help of SEM, we examined the apical surface of 6 defined areas, each of which was examined in 3 brains of different patients. This allowed us to compare the individual regions and to define apical surface of ECs.

\section{Material and methods}

In this study, we used tissue from 9 human brains of men and women aged 51 to 80 without any pathological evidence of the central nervous system (Tab. 1). Tissue sampling was performed in accordance with the Health Care Surveillance Authority and the Ethical Committee of the Faculty of Medicine, Comenius University and Bratislava University Hospital (number EK 62/2019).

The brains were sliced within 24 hours post mortem in the auxiliary device to obtain frontal brain slices of equal thickness $(0.5 \mathrm{~cm})$. The slices were numbered 1 to 19 . The first slice was performed at a distance of $2 \mathrm{~cm}$ from the frontal pole of the brain. The distance of each following frontal slice from the previous one was $0.5 \mathrm{~cm}$ and the last (19th) slice was at a distance of $11 \mathrm{~cm}$ from the frontal pole of the brain. The third ventricle was included in 5 (frontal) sections (Figs 1, 2), beginning in the region of the chiasma opticum. The exact regions of sampling, i.e. parts of the third brain ventricle walls, were defined in relation to periventricular structures as reference nerve tissue (18). We used atlases of the human brain for the terminology of individual periventricular structures, (19, 20) (Tab. 2) (Figs 1,2) and the previously published suggestion for the labelling of individual ependymal areas (18). The labelling consists of: 1) the designation of the third ventricle $(3 v), 2)$ the letter E (as ependyma), and 3) the abbreviation of

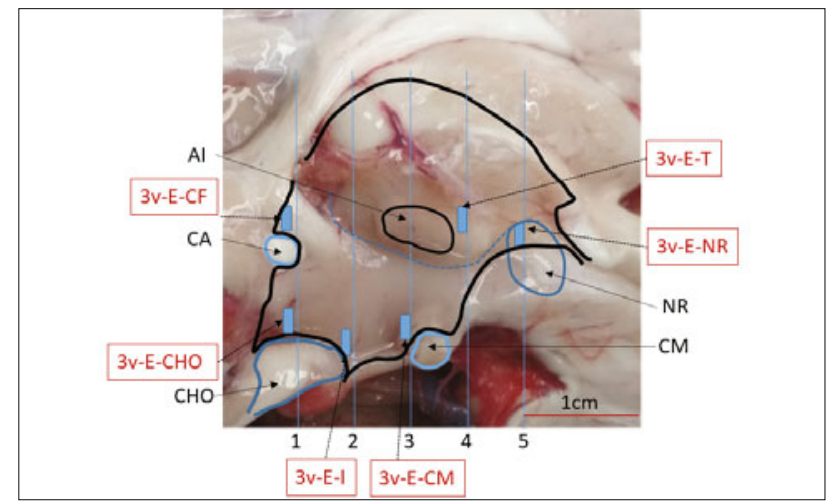

Fig. 2. Sagittal section of third ventricle with designated regions (see red rectangles) of examined ependymal lining, 1 - 5 correspond to frontal sections of the third ventricle (AI - adhesio interthalamica, CA - commissura anterior, CHO - chiasma opticum, CM - corpus mammillare, NR - nucleus ruber, for explanation of abbreviations also see Table 2).

the Latin name of the periventricular structure bordering the area of interest in the frontal slice. For example, the labelling of the ependyma over the chiasma opticum is $3 \mathrm{v}-\mathrm{E}-\mathrm{CHO}$. The final designations of the 6 examined ependymal areas are listed in Table 2.

After excision the samples (of up to $50 \mathrm{~mm}^{3}$ ) were fixed at room temperature by the solution of $3 \%$ glutaraldehyde in an 0.2 $\mathrm{M}$ phosphate buffer for 4 hours. After a triple wash with a $0.05 \mathrm{M}$ phosphate buffer, the samples were post-fixed by a $1 \%$ solution of osmium tetroxide, dehydrated in a graded ethanol series to 100 $\%$ ethanol, dried at critical point of $\mathrm{CO}_{2}$ using the BAL-TEC CPD 030 , sputter coated with a $15 \mathrm{~nm}$ gold layer in LEICA EM ACE 200, and examined with a SEM ZEISS EVO LS 15.

\section{Results}

With the help of SEM, we studied the apical surface of ECs in 6 examined areas (Tab. 2). Each area with a surface of $0.25 \mathrm{~mm}^{2}$ (which corresponds to apical surfaces of approximately $2500 \mathrm{ECs}$ ) was examined in 3 different patients. We focused on the shape and size of the apical membrane of the ECs and the presence of microvilli, cilia, short processes, and secretory bodies. We detected the presence of cilia, $0.3 \mu \mathrm{m}$ in width and of various lengths. Those longer than $3 \mu \mathrm{m}$ were designated as long cilia, while those equal to or shorter than $3 \mu \mathrm{m}$ were designated as short cilia. Cytoplasmic processes with a thickness of $0.3 \mu \mathrm{m}$ and a length less than $1 \mu \mathrm{m}$

Tab. 2. Designation of examined ependymal regions of the 3rd ventricle of five frontal slices defined in accordance with neighbouring periventricular structures ( $\mathrm{vw}$ - ventral wall, lw - lateral wall).

\begin{tabular}{lccccc}
\hline $\begin{array}{l}\text { Frontal section } \\
\text { of the 3rd ventricle }\end{array}$ & Wall & Periventricular structure & Abbreviation & Labelling of ependyma & Number of examined patient \\
\hline \multirow{2}{*}{1} & vw & columna fornicis & CF & 3v-E-CF & $2,3,5$ \\
\cline { 2 - 6 } & vw & chiasma opticum & CHO & 3v-E-CHO & $4,7,8$ \\
\hline 2 & vw & corpus mammillare & CM & 3v-E-I & $7,8,9$ \\
\hline 3 & lw & nucleus paraventricularis thalami & T & 3v-E-T & $3,6,8$ \\
\hline 4 & lw & nucleus ruber & NR & 3v-E-NR & $3,4,5$ \\
\hline 5 & & & & $1,3,8$ \\
\hline
\end{tabular}



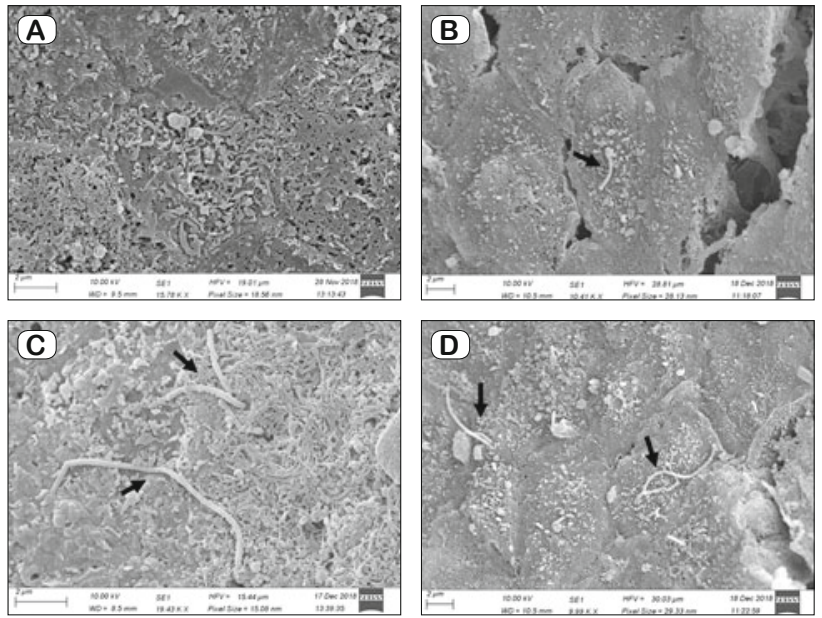

Fig. 3. A: ependymal cell (EC) without cilia (type 1), only microvilli are present B: EC with short cilium ( $<3 \mu \mathrm{m}$ in length) (type 2$) \mathrm{C}$ : on the bottom of the image - EC with one long cilium ( $\geq 3 \mu \mathrm{m}$ in length) (type 3) and on the top - EC with two short cilia (type 4) D: on the right side - EC with two long cilia (type 5), on the left side - EC with one short and one long cilium (type 6).
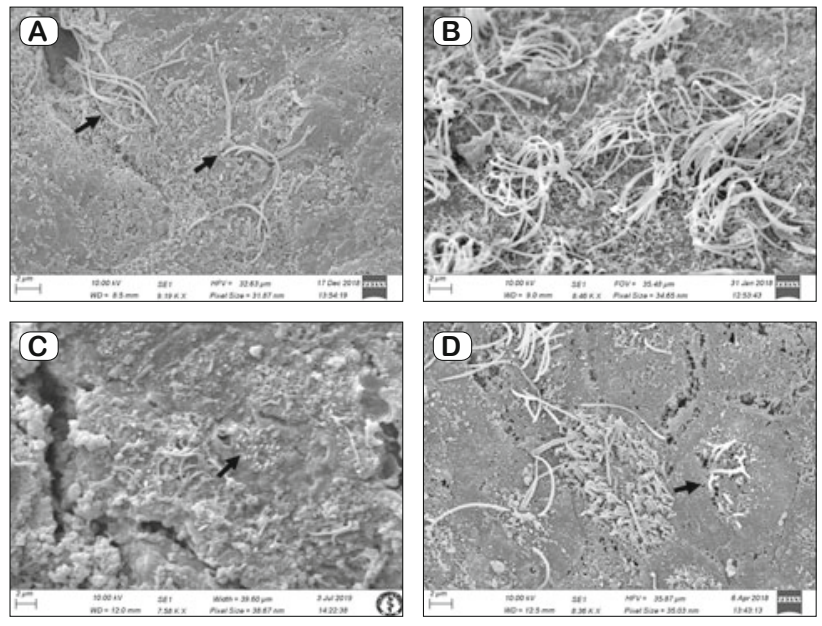

Fig. 4. A: on the right side of the image - ependymal cell (EC) with 3-7 cilia (type 7), on the left side - EC with 8-15 cilia (type 8) B: ECs with more than 15 cilia (type 9 - multi-ciliated ECs) C: on the right side EC with very short processes (type 11) D: on the right side - EC with short processes ( $<1 \mu \mathrm{m}$ in length) in combination with short cilia $(<3 \mu \mathrm{m}$ in length) (type 12).
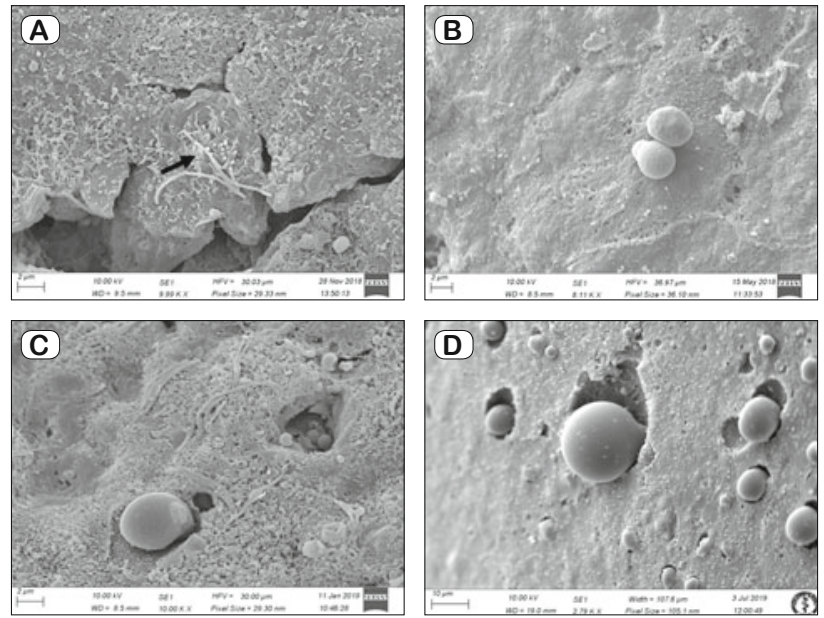

Fig. 5. A: ependymal cell (EC) with short processes ( $<1 \mu \mathrm{m}$ in length) and long cilia ( $\geq 3 \mu \mathrm{m}$ in length) (type 13) $B, C, D$ : presence of secretory vacuoles of different sizes on the ependymal surface.

were designated as short. We also detected the presence of microvilli with a thickness of $0.1 \mu \mathrm{m}$ and a length up to $1 \mu \mathrm{m}$. Based on the number and length of cilia present on the apical surface, we categorised the ECs into 13 different groups (Figs 3, 4, 5 and Tab. 4). We observed the surface area of $50 \times 50$ of neighbouring ECs. When we detected within this area any of 13 ependymal types, we marked its presence as positive $(+)$ into the table. If a specific ependymal type was present 10 and more times within a cluster of 100 neighbouring ECs, we marked its presence as increased (++). Our findings are summarised in Tables 3 and 4.

\section{6 distinct areas - results of SEM observations}

Area $3 v-E-C F$ was evaluated in patients 2, 3, and 5 (Tab. 1)

The apical surface of ECs in 3v-E-CF displayed a hexagonal, slightly elongated shape with dimensions of $11 \mu \mathrm{m}$ x $8 \mu \mathrm{m}$ (Fig. $6 \mathrm{~A})$. A comparison of the apical portions of ECs among the cohort of brains of three patients did not reveal the predominance of any type of cell in this specific area. The number of secretory bodies in all three brains of patients indicates that the secretory activity of ECs in this area was low.

Area $3 v-E-C H O$ was evaluated in patients 4, 7, and 8 (Tab. 1).

The apical surface of ECs in this area had a hexagonal shape

Tab. 3. Characteristics of apical surfaces of ECs in the examined patients (P) observed with a SEM in marked ependymal areas of the third human brain ventricle (+ positive presence, ++ elevated incidence).

\begin{tabular}{|c|c|c|c|c|}
\hline \multirow{3}{*}{ Labelled ependymal area } & \multicolumn{4}{|c|}{ Characteristics of apical surfaces of ependymal cells } \\
\hline & \multirow{2}{*}{ Shape of apical cell membrane } & \multirow{2}{*}{ Dimensions of apical cell membrane } & \multicolumn{2}{|c|}{ Obvious secretory bodies (sb) on the apical cell surfaces } \\
\hline & & & $\mathrm{sb} \leq 2 \mu \mathrm{m}$ & $\mathrm{sb}>2 \mu \mathrm{m}$ \\
\hline $3 \mathrm{v}-\mathrm{E}-\mathrm{CF}$ & hexagonal & $11 \times 8 \mu \mathrm{m}$ & $\mathrm{P} 3+\mathrm{P} 2+\mathrm{P} 5+$ & $\mathrm{P} 3$ - P2+ P5 - \\
\hline $3 v-\mathrm{E}-\mathrm{CHO}$ & hexagonal & $10 \times 8 \mu \mathrm{m}$ & P8+ P4+ P7+ & $\mathrm{P} 8+\mathrm{P} 4+\mathrm{P} 7+$ \\
\hline $3 v-E-I$ & hexagonal & $9 \times 9 \mu \mathrm{m}$ & $\mathrm{P} 8++\mathrm{P} 9++\mathrm{P} 7++$ & $\mathrm{P} 8+\mathrm{P} 9+\mathrm{P} 7+$ \\
\hline $3 v-E-C M$ & hexagonal & $6 \times 5 \mu \mathrm{m}$ & $\mathrm{P} 8+\mathrm{P} 6++\mathrm{P} 3+$ & P8- P6+ P3+ \\
\hline $3 v-E-T$ & hexagonal & $8 \times 8 \mu \mathrm{m}$ & $\mathrm{P} 3+\mathrm{P} 5+\mathrm{P} 4++$ & $\mathrm{P} 3+\mathrm{P} 5+\mathrm{P} 4++$ \\
\hline $3 v-E-N R$ & hexagonal & $10 \times 9 \mu \mathrm{m}$ & $\mathrm{P} 8++\mathrm{P} 1++\mathrm{P} 3++$ & $\mathrm{P} 8++\mathrm{P} 1+\mathrm{P} 3+$ \\
\hline
\end{tabular}


Tab. 4. Incidence of various types of ECs in the examined patients $(P)$ according to the presence of cilia and various sized processes on the apical surface of ECs in the examined areas of the third human brain ventricle (+ positive presence, ++ elevated incidence).

\begin{tabular}{|c|c|c|c|c|c|c|}
\hline \multirow{2}{*}{$\begin{array}{l}\text { Apical membrane of ependymal cells } \\
\text { according to the number and type of cilia }\end{array}$} & \multicolumn{6}{|c|}{ Labelled ependymal area } \\
\hline & $3 v-E-C F$ & $3 v-\mathrm{E}-\mathrm{CHO}$ & $3 v-E-I$ & $3 v-E-C M$ & $3 v-E-T$ & $3 v-E-N R$ \\
\hline \multirow{2}{*}{$\begin{array}{l}\text { without cilia, only microvilli are present } \\
\text { (type } 1 \text { ) }\end{array}$} & P3 P2 P5 & P8 P4 P7 & P8 P9 P7 & P8 P6 P3 & P3 P5 P4 & P8 P1 P3 \\
\hline & +++++ & ++++++ & ++++++ & ++++ & +++++ & +++++ \\
\hline \multirow{2}{*}{$\begin{array}{l}1 \text { short cilium } \\
\text { (type } 2 \text { ) }\end{array}$} & P3 P2 P5 & P8 P4 P7 & P8 P9 P7 & P8 P6 P3 & P3 P5 P4 & P8 P1 P3 \\
\hline & +++++ & ++++++ & ++++++ & ++++ & +++++ & +++++ \\
\hline \multirow{2}{*}{$\begin{array}{l}1 \text { long cilium } \\
\text { (type } 3 \text { ) }\end{array}$} & P3 P2 P5 & P8 P4 P7 & P8 P9 P7 & P8 P6 P3 & P3 P5 P4 & P8 P1 P3 \\
\hline & +++++ & ++++++ & +++++ & +++ & +++++ & ++++ \\
\hline \multirow{2}{*}{$\begin{array}{l}2 \text { short cilia } \\
\text { (type } 4 \text { ) }\end{array}$} & P3 P2 P5 & P8 P4 P7 & P8 P9 P7 & P8 P6 P3 & P3 P5 P4 & P8 P1 P3 \\
\hline & +++ & ++++++ & ++++ & ++++ & +++++ & +++ \\
\hline \multirow{2}{*}{$\begin{array}{l}2 \text { long cilia } \\
\text { (type } 5 \text { ) }\end{array}$} & P3 P2 P5 & P8 P4 P7 & P8 P9 P7 & P8 P6 P3 & P3 P5 P4 & P8 P1 P3 \\
\hline & +++ & ++++++ & ++++ & +++ & +++++ & +++ \\
\hline \multirow{2}{*}{$\begin{array}{l}1 \text { short and } 1 \text { long cilium } \\
\text { (type } 6 \text { ) }\end{array}$} & P3 P2 P5 & P8 P4 P7 & P8 P9 P7 & P8 P6 P3 & P3 P5 P4 & P8 P1 P3 \\
\hline & +++ & ++++++ & ++++ & +++ & +++++ & +++ \\
\hline (type 7) & +++ & +++++ & +++ & +++ & +++++ & +++ \\
\hline \multirow{2}{*}{$\begin{array}{l}8-15 \text { cilia } \\
\text { (type } 8 \text { ) }\end{array}$} & P3 P2 P5 & P8 P4 P7 & P8 P9 P7 & P8 P6 P3 & P3 P5 P4 & P8 P1 P3 \\
\hline & +++++ & ++++ & ++++ & +++ & +++ & ++++ \\
\hline \multirow{2}{*}{$\begin{array}{l}\text { more than } 15 \text { cilia } \\
\text { (type 9) }\end{array}$} & P3 P2 P5 & P8 P4 P7 & P8 P9 P7 & P8 P6 P3 & P3 P5 P4 & P8 P1 P3 \\
\hline & +++++ & ++++ & ++++ & +++ & ++++ & ++++ \\
\hline \multirow{2}{*}{$\begin{array}{l}\text { short and long cilia } \\
\text { (type } 10)\end{array}$} & P3 P2 P5 & P8 P4 P7 & P8 P9 P7 & P8 P6 P3 & P3 P5 P4 & P8 P1 P3 \\
\hline & +++ & +++ & +++ & +++ & +++ & ++++ \\
\hline \multirow{2}{*}{$\begin{array}{l}\text { short processes only } \\
\text { (type 11) }\end{array}$} & P3 P2 P5 & P8 P4 P7 & P8 P9 P7 & P8 P6 P3 & P3 P5 P4 & P8 P1 P3 \\
\hline & +++++ & ++++++ & ++++++ & ++++ & ++++ & ++++ \\
\hline \multirow{2}{*}{$\begin{array}{l}\text { short processes with short cilia } \\
\text { (type 12) }\end{array}$} & P3 P2 P5 & P8 P4 P7 & P8 P9 P7 & P8 P6 P3 & P3 P5 P4 & P8 P1 P3 \\
\hline & +++ & ++++ & +++ & ++++ & +++ & +++ \\
\hline \multirow{2}{*}{$\begin{array}{l}\text { short processes with long cilia } \\
\text { (type } 13 \text { ) }\end{array}$} & P3 P2 P5 & P8 P4 P7 & P8 P9 P7 & P8 P6 P3 & P3 P5 P4 & P8 P1 P3 \\
\hline & +++ & +++ & +++ & +++ & +++ & +++ \\
\hline
\end{tabular}
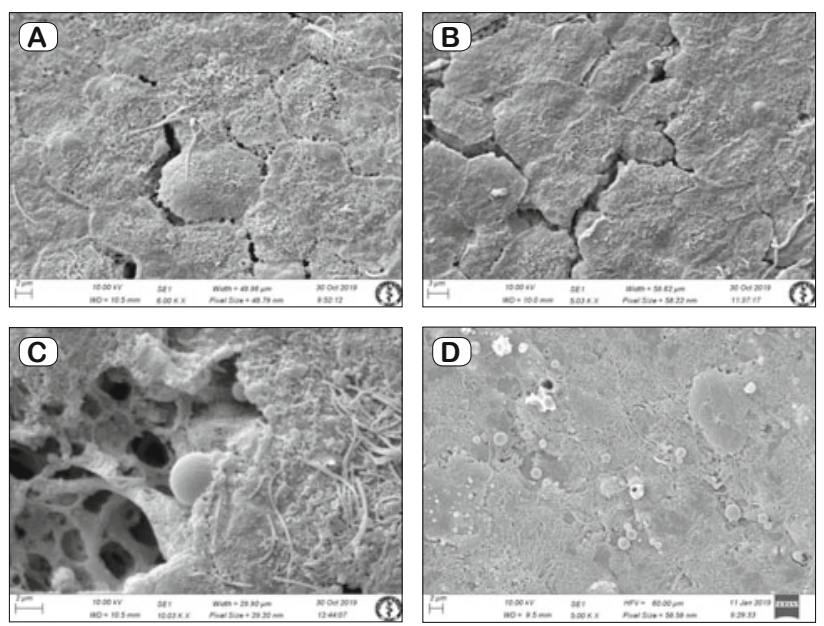

Fig. 6. A: hexagonal shape of ECs (3v-E-CF) B: area with rare incidence of cilia ( $3 \mathrm{v}-\mathrm{E}-\mathrm{CHO}) \mathrm{C}$ : secretory body protruding from the $\mathrm{EC}$ lateral surface (3v-E-I) D: ependymal surface with obvious secretory activity (3v-E-I).

with dimensions of $10 \mu \mathrm{m} \times 8 \mu \mathrm{m}$. Based on the observations of brains of all three patients, we characterised the apical surface of ECs from this area as non-ciliated with short processes or containing few cilia (types 1-7, 11, and 12 in Table 4) (Fig. 6B). The secretory activity of these cells was minimal.
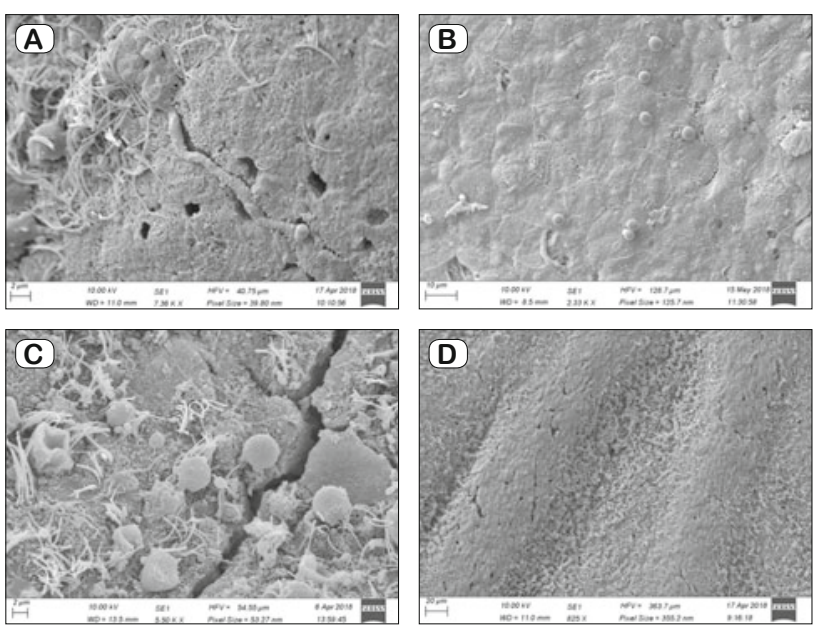

Fig. 7. A: supraependymal cell in 3v-E-CM B: apical surfaces of ECs with little or no cilia and with the presence of secretory bodies in $3 \mathrm{v}-\mathrm{E}$ T C: presence of cilia, microvilli and secretory bodies on apical surface in 3v-E-NR D: ciliated ependymal surface in 3V-E-NR.

Area $3 v-E-I$ was evaluated in patients 7, 8, and 9 (Tab. 1).

The apical membrane of ECs in this area was of a hexagonal, sometimes irregular shape with dimensions of $9 \mu \mathrm{m} \times 9 \mu \mathrm{m}$. Numerous secretory bodies were present on the surface of ECs coming from the depth or originating from the lateral or apical surface 
437-443

(Fig. 6C). Thus, we designated this area as having high secretory activity (Fig. 6D). The ECs displayed a smaller number of cilia (types 1, 2, and, 11 in Table 4). The ventricular surface of patient 7 was slightly folded with ECs with a higher number of cilia dominating on ridges, while less ciliated cells occupied the grooves.

Area $3 v-E-C M$ was evaluated in patients 3, 6, and 8 (Tab. 1).

Based on the study of the apical surface of ECs in 3v-E-CM, the ECs in all three examined patients had the dimensions of apical surfaces of $5 \mu \mathrm{m} \times 6 \mu \mathrm{m}$, which is less in comparison to $3 \mathrm{v}$ e-CF, $3 \mathrm{v}-\mathrm{e}-\mathrm{CHO}, 3 \mathrm{v}-\mathrm{e}-\mathrm{I}, 3 \mathrm{v}-\mathrm{e}-\mathrm{T}$ and $3 \mathrm{v}-\mathrm{e}-\mathrm{NR}$. This seems to be due to the higher density of ECs in this area. In brains of all three patients, there were locations with ECs which showed a large number of cilia on its apical surface (EC types 8, 9, 10 according to Tab. 4) and locations with little or no cilia (ECs type 1, 2, 3, 4, 11). The ratio of more to less ciliated locations varied in individual patients. Secretory bodies were more or less present in brains of all three patients. In patient No. 3, the surface of the ventricular wall in 3v-E-CM was slightly folded, and ECs in elevated areas of ridges displayed less cilia, compared to deeper areas of grooves which possessed numerous cilia on the apical surfaces of the ECs. We also observed the presence of supraependymal cells (Fig. 7A).

Area $3 v-E-T$ was evaluated in patients 3, 6, and 8 (Tab. 1).

The shape of the apical membranes of ECs in this area was regular and hexagonal with a diameter of approximately $8 \mu \mathrm{m}$. When considering the results of $3 \mathrm{v}-\mathrm{E}-\mathrm{T}$ from brains of all three patients, that was characterised by the presence of secretory bodies with a diameter smaller as well as larger than $2 \mu \mathrm{m}$ (Fig. 7B), which could indicate a high secretory activity. Although in general, ECs with a small number of cilia dominated in this area (types 1-7, 11 according to Tab. 4), the folded surface of patient No. 3 contained alternating locations of high number (especially in grooves) and low number of cilia.

Area $3 v-E-N R$ was evaluated in patients 1,3 , and 8 (Tab. 1).

The shape of the apical surfaces of ECs in this area was slightly elongated and hexagonal with dimensions of $10 \times 9 \mu \mathrm{m}$. Numerous secretory bodies were present in all three examined patients, which could indicate high secretory activity (Fig. 7C). Large groups of ECs with a very small number of cilia were mostly identified, but there were also locations rich in cilia. The border between these various groups of ECs was more pronounced in comparison with other areas examined by us, where the areas with a smaller and greater density of cilia also alternated (for example $3 \mathrm{v}-\mathrm{E}-\mathrm{T}$ ). In patient 3 we observed a folded ependymal surface, while EC types with a greater number of cilia (types 7-10 and 13 according to Tab. 4) prevailed in recesses, and ECs with little or no cilia or with short processes prevailed on the elevated surface (types 1-6, 11 and 12 according to Tab. 4) (Fig. 7D).

\section{Discussion}

It is obvious from our study that the nature of the ependymal lining surface is heterogeneous. In order to be able to relevantly compare the results of studies of ECs, the location from which the sample of examined ependyma was taken must be precisely defined. We marked the examined ependymal regions of the third human brain ventricle based on the presence of periventricular structures (Fig. 1, 2, Tab. 2) (7, 21).

Using SEM, we examined the apical surface of ECs of the third human brain ventricle in six precisely designated locations, and examined them in brains of three patients (Tabs 1 and 2). We observed cilia, microvilli, very short processes and secretory bodies on the surface of ECs. We also occasionally observed supraependymal nerve fibres and cells which we did not specify.

The cilia of individual ECs varied in number and length (Tab. 4), had a smooth surface and the same diameter of $0.3 \mu \mathrm{m}$ throughout their entire length. Mirzadeh et al (10) defined three basic groups of ECs according to their apical surface morphology: E1 cells - multi-ciliated ependymocytes with motile cilia (we labelled them as type 9), E2 cells - bi-ciliated ECs with one to two motile cilia (we divided these according to cilia length and labelled them as types 4, 5, 6), and E3 cells - uni-ciliated ECs with primary cilium (which we labelled according to the length of the cilium as types 2 and 3). E2 and E3 cells contain a long basal process thanks to which various signals reach more distant locations in the brain. The cilia of E2 and E3 cells most probably have a sensory function for CSF metabolites; they are responsible for the capture and transduction of various extracellular signals and contribute to the regulation of the progenitor activity of hypothalamic neurons controlling the energy balance (22). Cilia of multi-ciliated ECs help with the flow of the CSF. We subdivided the multi-ciliated ECs into ECs with 3-7 cilia (type 7), ECs with 8-15 cilia (type 8) and ECs with more than 15 cilia (type 9). We also found ECs with no cilia, where only microvilli were present (we labelled them as type 1). Certain ECs with no cilia showed very short processes with a thickness of approximately $0.3 \mu \mathrm{m}$ and up to $1 \mu \mathrm{m}$ in length on the surface. Using SEM, these structures were also observed by Bruni et al (15) in the infundibular recess (IR) of rabbits and in the third brain ventricle of humans and were marked as "knob-like protrusions". We observed ECs with short processes in all examined locations and labelled them as type 11 (Tab. 4). We observed them more frequently in locations with a smaller number of cilia. However, in the area with denser ciliary cover, this may significantly impair the observation of smaller apical structures such as short processes, microvilli, and small secretory bodies. Short processes on the apical surface of the ECs were also observed in combination with short or long cilia and were labelled as types 12 and 13. In Table 4 we summarized the overview of all ECs types according to the presence of the various number of cilia, microvilli, and short processes and their presence in the six examined regions within the third brain ventricle in three examined patients.

The observed secretory bodies of various sizes and unknown content indicate a secretory function in some ECs. 3v-E-I and $3 \mathrm{v}-$ E-NR appear to have the highest secretory activity within the examined regions of the third human brain ventricle. The incidence of secretory bodies and the shape and size of the apical surface of ECs in the six examined regions are summarized in Table 3.

Scott et al (16) used SEM to analyse the third human brain ventricle. The dorsal third was covered by a large number of cilia that overlapped other possibly present structures. More ventrally, in the central third of the third ventricle, they observed a slight de- 
cline in cilia density and an appearance of microvilli and "rounded lucent excrescences". They characterized the ventral third of the third ventricle with an infundibular recess as almost free of cilia but with the presence of numerous microvilli and "large lucent excrescences". Our examined areas (3v-E-CF, 3v-E-T a 3v-E-NR) correspond with the central third of the third ventricle in the dorsalventral axis (Figs 1,2). In terms of all three areas, locations with a low and high number of cilia alternated here, and in $3 \mathrm{v}$-E-NR the transitions between multiciliated and little ciliated locations were the most obvious. The "rounded lucent excrescences" correspond to secretory bodies in the examined samples. According to our observations, $3 \mathrm{v}$-E-CF was the least active in terms of secretion in contrast to $3 \mathrm{v}$-E-NR, which showed a high secretory activity. In general, our results correspond to previous observations $(15,16)$, although we precisely specified and defined the observed regions. $3 \mathrm{v}-\mathrm{E}-\mathrm{CHO}, 3 \mathrm{v}-\mathrm{E}-\mathrm{I}$ and $3 \mathrm{v}-\mathrm{E}-\mathrm{CM}$, which we examined and clearly defined, correspond to the ventral third of the brain ventricle. In general, we noticed the low number of cilia and higher number of microvilli in this area; however, if we take into consideration the individual examined regions separately, this statement does not equally apply for all locations and all patients. For example, we also found locations in 3v-E-CM and 3v-E-I with an abundant incidence of cilia. The secretory activity within the ventral third of the brain ventricle was most distinctive in $3 \mathrm{v}-\mathrm{E}-\mathrm{I}$, which corresponds to previous observations in humans and animals $(15,16)$. However, according to our observations, the secretory activity derived from the number of observed secretory bodies in $3 \mathrm{v}$-E-I was comparable with $3 \mathrm{v}-\mathrm{E}-\mathrm{NR}$ in the central third of the brain ventricle (Tab. 3).

When observing the folds of the ventricular surface we repeatedly noticed ECs with numerous cilia in grooves and ridges that were covered by ECs with little or no cilia. This finding was independent of the location of the examined ependymal area; we found it in $3 \mathrm{v}-\mathrm{E}-\mathrm{I}, 3 \mathrm{v}-\mathrm{E}-\mathrm{CM}, 3 \mathrm{v}-\mathrm{E}-\mathrm{T}$, and $3 \mathrm{v}-\mathrm{E}-\mathrm{NR}$. In our opinion, the numerous cilia in grooves could be related to the increased need to prevent liquor flow stagnation, while individual cilia on the surfaces of ridges could represent a sensory function. Mirzadeh et al (10) attribute such function to uni- and bi-ciliated ECs.

The apical surface of the ependymal lining of the third brain ventricle is extremely heterogeneous. Significant heterogeneity was also observed in individual evaluated ependymal regions, where we found all types of apical surfaces. The systematic mapping of the ventricular surface significantly contributes to the clarification of ECs functions in individual locations.

\section{References}

1. Sarnat HB. Role of human fetal ependyma. Pediatr Neurol 1992 b; 8 (3): $163-178$.

2. Bruni JE, Del Bigio MR, Clattenburg RE. Ependyma: normal and pathological. A review of the literature. Brain Res 1985; 356 (1): 1-19.

3. Bruni JE. Ependymal development, proliferation, and functions: a review. Microsc Res Tech 1998; 41 (1): 2-13.

4. Coletti AM, Singh D, Kumar S et al. Characterization of the ventricular-subventricular stem cell niche during human brain development. Development 2018; 145 (20).
5. Del Bigio MR. Ependymal cells: biology and pathology. Acta Neuropathol 2010; 119 (1): 55-73.

6. Mathew TC. Scanning electron microscopic observations on the third ventricular floor of the rat following cervical sympathectomy. Folia Morphol (Warsz) 2007; 66 (2): 94-99.

7. Mitro A, Kiss A. Ependymal tables designated for differentiation of the ependyma based on the adjacent periventricular structures. Biologia 2016; 71 (5): 603-611.

8. Mitro A, Polák Š, Filipčík P. Ependyma of the human brain ventricles. Giza: El-Meleigy Press, 2008: 1-100.

9. Mirzadeh Z, Merkle FT, Soriano-Navarro M, Garcia-Verdugo JM, Alvarez-Buylla A. Neural stem cells confer unique pinwheel architecture to the ventricular surface in neurogenic regions of the adult brain. Cell Stem Cell 2008; 3: 265-278.

10. Mirzadeh Z, Kusne Y, Duran-Moreno $M$ et al. Bi- and uniciliated ependymal cells define continuous floor-plate-derived tanycytic territories. Nat Commun 2017; 8: 13759.

11. Mathew TC. Regional analysis of the ependyma of the third ventricle of rat by light and electron microscopy. Anat Histol Embryol 2008; 37 (1): 9-18.

12. Ray PK, Choudhury SR. Changes in the surface fine structure of ependyma of the rat third ventricle following operative leakage of cerebrospinal fluid. J Anat 1985; 140 (1): 1-11.

13. Scott DE, Sladek JR Jr. Age related changes in the endocrine hypothalamus: I. Tanycytes and the blood-brain-cerebrospinal fluid barrier. Neurobiol Aging 1981; 2 (2): 89-94.

14. Haemmerle CA, Nogueira MI, Watanabe IS. The neural elements in the lining of the ventricular-subventricular zone: making an old story new by high-resolution scanning electron microscopy. Front Neuroanat 2015; 9 (134)

15. Bruni JE, Montemurro DG, Clattenburg RE, Singh RP. A scanning electron microscopic study of the ependymal surface of the third ventricle of the rabbit, rat, mouse and human brain. Anat Rec 1972; 174 (4): 407-420.

16. Scott DE, Paull WK, Dudley GK. A comparative scanning electron microscopicanalysis of the human cerebral ventricular system. I. The third ventricle. Zellforsch Mikrosk Anat 1972; 132 (2): 203-215.

17. Choudhury SR, Azzam NA, Donohue JM. Changes in the surface fine structure of rat third ventricular ependyma following chronic acetazolamide treatment. J Anat 1979; 129 (1): 51-62.

18. Mitro A. Method of labelling of individual ependymal areas according to periventricular structures of the rat lateral brain ventricles. Biologia 2014; 69 (9): 1250-1254.

19. Mai JK, Assheuer J, Paxinos G. Atlas of the human brain. San Diego, London, Boston, New York, Sydney,Tokyo, Toronto: Academic Press. Harcourt Brace \& Company., 1997.

20. Ding SL, Royall JJ, Sunkin SM et al. Comprehensive CellularResolution /Atlas of the Adult Human Brain. J Comp Neurol 2016; 524: $3127-3481$.

21. Mitro A, Lorencová M, Mikušová R, Gálfiová $P$, Kútna V, Polák Š. Labelling of individual ependymal areas in the third and fourth ventricle of the human brain: ependymal tables Biologia 2019; 74: 533-541.

22. Lee DA, Bedont JL, Pak T et al. Tanycytes of the hypothalamic median eminence form a diet-responsive neurogenic niche. Nat Neurosci 2012; 15 (5): 700-702.

Received January 28, 2020. Accepted March 31, 2020. 